\title{
Comparing etoricoxib and celecoxib for preemptive analgesia for acute postoperative pain in patients undergoing arthroscopic anterior cruciate ligament reconstruction: a randomized controlled trial
}

\author{
Tanarat Boonriong $^{1 *}$, Boonsin Tangtrakulwanich', Prapakorn Glabglay', Sasikaan Nimmaanrat ${ }^{2}$
}

\begin{abstract}
Background: The efficacy of selective cox-2 inhibitors in postoperative pain reduction were usually compared with conventional non-selective conventional NSAIDs or other types of medicine. Previous studies also used selective cox-2 inhibitors as single postoperative dose, in continued mode, or in combination with other modalities. The purpose of this study was to compare analgesic efficacy of single preoperative administration of etoricoxib versus celecoxib for post-operative pain relief after arthroscopic anterior cruciate ligament reconstruction.

Methods: One hundred and two patients diagnosed as anterior cruciate ligament injury were randomized into 3 groups using opaque envelope. Both patients and surgeon were blinded to the allocation. All of the patients were operated by one orthopaedic surgeon under regional anesthesia. Each group was given either etoricoxib 120 mg., celecoxib 400 mg., or placebo 1 hour prior to operative incision. Post-operative pain intensity, time to first dose of analgesic requirement and numbers of analgesic used for pain control and adverse events were recorded periodically to 48 hours after surgery. We analyzed the data according to intention to treat principle.

Results: Among 102 patients, 35 were in etoricoxib, 35 in celecoxib and 32 in placebo group. The mean age of the patients was 30 years and most of the injury came from sports injury. There were no significant differences in all demographic characteristics among groups. The etoricoxib group had significantly less pain intensity than the other two groups at recovery room and up to 8 hours period but no significance difference in all other evaluation point, while celecoxib showed no significantly difference from placebo at any time points. The time to first dose of analgesic medication, amount of analgesic used, patient's satisfaction with pain control and incidence of adverse events were also no significantly difference among three groups.
\end{abstract}

Conclusions: Etoricoxib is more effective than celecoxib and placebo for using as preemptive analgesia for acute postoperative pain control in patients underwent arthroscopic anterior cruciate ligament reconstruction.

Trial registration number: NCT01017380

\section{Background}

Multimodal or balanced analgesia, using a combination of analgesics throughout the perioperative period to control postoperative pain, has been increasingly popular

\footnotetext{
* Correspondence: tanarat.b@psu.ac.th

'Department of Orthopaedic Surgery and Physical Medicine, Faculty of Medicine, Prince of Songkla University, Hat Yai, Songkhla, Thailand Full list of author information is available at the end of the article
}

and well accepted [1,2]. Nonsteroidal anti-inflammatory drugs (NSAIDs) have a significant role in postoperative pain control as they reduce the use of opioids [3-5] which were associated with a variety of postoperative side effects, such as ventilatory depression, drowsiness and sedation, nausea and vomiting, pruritus, urinary retention, ileus and constipation [6,7]. The nonselective NSAIDs inhibit both forms of the cycloxygenase (COX) 
enzymes. The efficacy of NSAIDs for the treatment of pain is due to the inhibition of the COX-2 enzyme, whereas the inhibition of the COX-1 enzyme may lead to disturbance of normal platelet function and gastrointestinal toxicity $[8,9]$. Selective COX-2 inhibitors offer significantly less gastrointestinal toxicity and no effects on platelet aggregation [10], therefore are more suitable for perioperative use. A number of studies have shown that these selective COX-2 inhibitors are effective in reducing pain in postoperative period [3-5,7,11-17] and more effective if given both before and after surgery $[5,18]$. From meta-analysis, a single oral dose of either etoricoxib or celecoxib is an effective means of postoperative pain relief $[19,20]$. However, we could not find any study of efficacy of single oral dose of these medicines given preoperatively. Furthermore, the comparisons where usually made between selective cox-2 inhibitors and conventional NSAIDs or other medicines. There has been no head-to-head comparison study between these two novel selective COX-2 inhibitors in terms of postoperative pain reduction. The purposes of this study comparing the efficacy of preoperative administrations of etoricoxib versus celecoxib and placebo for post-operative pain relief after arthroscopic anterior cruciate ligament reconstruction are to evaluate the efficacy of single preoperative dose of selective cox-2 inhibitors and whether there is any superiority among selective cox- 2 inhibitors currently available in the market.

\section{Methods}

This study was approved by the Ethic Committee of our Faculty. The patients diagnosed as anterior cruciate ligament injury aged between 15 to 50 years old who scheduled for arthroscopic anterior cruciate ligament reconstruction (ACLR) in Songklanagarind hospital during January 2008-January 2009 was included in the study. We excluded the patients who had known allergy, sensitivity or contra-indications to opioids or NSAIDs, having a history of dyspepsia, peptic ulcer or abnormal bleeding, coronary and peripheral arterial diseases as well as allergy to sulfonamide group. The patients who had used NSAIDs, opioids, salicylate within 7 days of the operation were also excluded. The patients were randomized into 3 groups; etoricoxib,celecoxib and placebo using random table containing in the opaque envelope. In etoricoxib group, $120 \mathrm{mg}$ of etoricoxib was orally given. In celecoxib group, $400 \mathrm{mg}$ was given 1 hour before the incision as same as in the controlled group. Both the surgeon and the assessors were blinded to the result of allocation. As a currently common treatment protocol in our country where the hospital cost is inexpensive and for the purpose of direct pain observation, all patients were admitted a night before surgery and discharged at 48 hours post-operatively. The operations were performed under spinal anesthesia using
$0.5 \%$ hyperbaric bupivacaine without additional intrathecal opioid. The arthroscopic anterior cruciate ligament reconstructions were performed by the principle investigator using autograft bone-patellar tendon-bone. The operative time were recorded. At the end of the operation, all the remaining intra-articular fluid was squeezed out, a vacuum drain was placed intra-articularly and the operative wound was closed before the tourniquet was released. The total drain amount was recorded at 48 hours before removal.

All subjects were treated in routine fashion in the recovery room. They were kept until they recovered from the spinal anesthesia and satisfied with recovery room scoring system. The operated knees were locked at in full extension with hinge knee brace for 48 hours and allowed for 0-90 degrees motion at 48 hours when the drain had been removed and wound had been dressing changed. During the post-operative period, the patients were asked to quantify their pain using a Verbal Analog Pain Scale (VbAPS) of 0-100 mm. where 0 represents no pain and $100 \mathrm{~mm}$ for unbearable pain. The first pain evaluation was made just before they left the recovery room and then repeated at $4,8,12,16,20$, $24,30,36,42$ and 48 hours postoperatively. The postoperative pain medications allowed were oral paracetamol $1000 \mathrm{mg}$ taken as needed every 6 hours and/or intravenous fentanyl 1 microgram per kilogram taken every 3 hours as requested by patients. The time to first use of each analgesic medication was recorded. The total amount of both medications was recorded at 48 hours. The patients were also asked to grade their satisfaction with pain control at 48 hours using a Verbal Analog Pain Scale (VbAPS) of 0-100 mm, where 0 represent dissatisfy and $100 \mathrm{~mm}$ for most satisfy. The primary outcome of this study was a comparison of the postoperative pain levels in the three groups, while the secondary outcomes were the time to first analgesic analgesics, total amount of analgesics used, the amount of drain output (as represent blood loss) and patients' satisfaction with their pain control. The vital signs were recorded regularly. All adverse drug reactions and side effects were also recorded.

\section{Statistical analysis}

The sample size required for this study was 32 patients in each arm. The calculation relied on the primary outcome; post-operative pain intensity, which from previous study found the standard deviations of celecoxib and etoricoxib to be 0.2 and 0.3 , respectively. The sample size was based on a 2 -sided test with $80 \%$ power and a significant level of 0.05. All statistical calculation was performed using STATA version 9.0.We analyzed the data based on intention-to-treat principle. Either chi-square or Fisher's exact test was used to analyze categorical outcomes. Differences among 3 groups of continuous variables were 
Table 1 Patient characteristics among groups

\begin{tabular}{|c|c|c|c|c|}
\hline Characteristics & Etoricoxib & Celecoxib & Placebo & P-value \\
\hline Number & 35 & 35 & 32 & \\
\hline Sex: Male (\%) & $33(94.29)$ & $31(88.57)$ & $28(87.50)$ & 0.375 \\
\hline Mean duration of injury (SD) & $18.22(15.93)$ & $28.31(44.87)$ & $35.41(49.23)$ & 0.477 \\
\hline Associated injury & & & & 0.234 \\
\hline None & $9(25.71)$ & $7(20.00)$ & $9(28.13)$ & \\
\hline Medial meniscus & $16(45.71)$ & $17(48.57)$ & $10(31.25)$ & \\
\hline Lateral meniscus & $5(14.30)$ & $7(20.00)$ & $6(18.75)$ & \\
\hline Both meniscus & $2(5.71)$ & $1(2.86)$ & $7(21.88)$ & \\
\hline Articular injury & $2(5.71)$ & $2(5.71)$ & $0(0)$ & \\
\hline Both meniscus and articular injury & $1(2.86)$ & $1(2.86)$ & $0(0)$ & \\
\hline Concomitant surgery & & & & 0.75 \\
\hline None & $13(37.15)$ & $13(37.14)$ & $13(40.63)$ & \\
\hline Medial menisectomy & $13(37.15)$ & $11(31.43)$ & $10(31.25)$ & \\
\hline Lateral menisectomy & $3(5.87)$ & $5(14.29)$ & $6(18.75)$ & \\
\hline Both medial and lateral menisectomy & $2(5.71)$ & $0(0)$ & $2(6.06)$ & \\
\hline Cartilage debridement & $2(5.71)$ & $5(14.29)$ & $2(6.25)$ & \\
\hline Mean pain score before surgery (SD) & $11.17(17.76)$ & $14.0(21.58)$ & $15.62(26.39)$ & 0.721 \\
\hline Mean operative time (SD) & $52.50(10.76)$ & $60.73(14.20)$ & $60.45(20.30)$ & 0.223 \\
\hline Mean tourniquet time (SD) & $56.08(9.69)$ & $63.25(12.84)$ & $63.90(19.33)$ & 0.089 \\
\hline - Mean drain output at $24 \mathrm{hr} . / \mathrm{ml}$ (SD) & $170.77(183.68)$ & 218.94(231.48) & $143.28(106.40)$ & 0.663 \\
\hline
\end{tabular}

analyzed by analysis of variance (ANOVA). Post-hoc analysis was performed with Bonferroni test.

\section{Results}

Among 102 patients, 35 were in etoricoxib, 35 in celecoxib and 32 in placebo group. The mean age of the patients was 30 years and most of the injury came from sports injury. There were no significant differences among groups in all demographic characteristics. The duration of injury, associated injuries, concomitant surgeries, mean operative and tourniquet time, and mean drain output were also no differences among groups (Table 1). There were no differences among groups for the time to first dose of analgesic medication, amount of paracetamol and fentanyl used, and patient satisfaction with pain control (Table 2). Although there were significantly higher reports of constipation and fever in placebo group, there was no significant difference in the numbers of adverse event among the three groups (Table 3). The etoricoxib group had significantly less pain intensity than the other two groups at recovery room and up to 8 hours period but no significance difference in all other evaluation point, while celecoxib showed no significantly difference from placebo at any time point (Figure 1).

\section{Discussion}

Postoperative pain following arthroscopic ACL reconstruction could be perceived by the patients immediately in the recovery room as they were recovering from spinal anesthesia, rose to peak intensities around 8 hours and slowly decreased to acceptable level below 40 after 36 hours postoperatively. We found that only etoricoxib, not celecoxib, was effective for use as preemptive analgesia in patients undergoing arthroscopic ACL reconstruction. However, the time to first dose of analgesic medication, total amount of analgesics used, and patient's satisfaction with pain control were also not significantly different among the three groups.

Preemptive analgesia is a new strategy of postoperative pain management. The key concept is to prevent the altered sensory processing from surgical process. There are a number of medications being tested for this

Table 2 Medication usages and patient satisfaction among groups

\begin{tabular}{|c|c|c|c|c|}
\hline Variables & Etoricoxib & Celecoxib & Placebo & P-value \\
\hline \multicolumn{5}{|l|}{ Mean number of rescue medication (SD) } \\
\hline - Paracetamol (Tabs.500 mg.) & $3.05(2.44)$ & $3.50(2.83)$ & $4.65(3.49)$ & 0.648 \\
\hline - Amount of fentanyl use (micrograms) & $114.64(89.99)$ & $112.8(84.43)$ & $171.43(129.56)$ & 0.222 \\
\hline Time to first dose of fentanyl (hr) & $5.89(5.67)$ & $5.83(10.22)$ & $5(5.85)$ & 0.55 \\
\hline Mean pain satisfaction score & $78.14(14.04)$ & $80.68(16.86)$ & $72.22(18.36)$ & 0.167 \\
\hline
\end{tabular}


Table 3 Adverse events among groups

\begin{tabular}{lrrrr}
\hline Adverse events & Etoricoxib & Celecoxib & Placebo & P-value \\
\hline - Gastrointestinal & & & & \\
Dyspepsia & $1(2.85)$ & $0(0)$ & $2(6.25)$ & 0.436 \\
Flatulence & $0(0)$ & $0(0)$ & $1(3.13)$ & 0.205 \\
Nausea & $1(2.85)$ & $0(0)$ & $0(0)$ & 0.233 \\
$\quad$ Vomiting & $0(0)$ & $0(0)$ & $2(6.25)$ & 0.07 \\
$\quad$ Constipation & $0(0)$ & $0(0)$ & $3(9.38)$ & $0.025^{*}$ \\
- Neurological & & & & \\
$\quad \begin{array}{l}\text { Dizziness } \\
\text { Headache }\end{array}$ & $3(8.57)$ & $2(5.71)$ & $4(12.50)$ & 0.59 \\
- Cardiovascular & $0(0)$ & $1(2.85)$ & $2(6.25)$ & 0.133 \\
$\quad \begin{array}{l}\text { Tachycardia } \\
\text { Hypertension }\end{array}$ & $2(5.71)$ & $0(0)$ & $3(9.38)$ & 0.52 \\
- Renal & $3(8.57)$ & $2(5.71)$ & $5(15.63)$ & 0.35 \\
$\quad$ Oliguria & & & & \\
- Other & $0(0)$ & $0(0)$ & $1(3.13)$ & 0.205 \\
$\quad$ Fever & $2(5.71)$ & $12(34.29)$ & $11(34.38)$ & $0.005^{*}$ \\
\hline
\end{tabular}

* Statistically significant among groups.

strategy, including opioids, anesthetic drugs and NSAIDs with conflicting results $[3-5,7,21,22]$. Although there have been some studies evaluating the efficacy of NSAIDs for preemptive analgesia, our study is the first head-to-head study of using COX-2 inhibitor NSAIDs for preemptive analgesia for major orthopaedic surgery. Our results found that only etoricoxib was efficacious for use as preemptive analgesia after major orthopaedic surgery. Efficacy of etoricoxib over celecoxib and the placebo may explained by the better or stronger analgesic efficacy of this drug. Other study had also demonstrated the efficacy of etoricoxib for perioperative pain control. Rasmussen et al use etoricoxib $120 \mathrm{mg} /$ day from day 1 to day 7 postoperatively in the patient undergoing arthroplasty [17]. They found that etoricoxib provided analgesia that was similar to controlled-release naproxen sodium on day 1 and superior to placebo with reduced supplement opioid used over 7 days [17].

The only head-to-head comparison between etoricoxib and celecoxib was in study of Bingham III, et al. [23] who compared the efficacy of etoricoxib $30 \mathrm{mg}$ with the generally maximum recommended dose of celecoxib, $200 \mathrm{mg}$, in the treatment of osteoarthritis (OA) in two identically designed studies. They concluded that etoricoxib $30 \mathrm{mg}$ per day was at least as effective as celecoxib $200 \mathrm{mg}$ per day and had similar safety in the treatment of knee and hip OA; both were superior to placebo [23]. Our study reached a contrast conclusion that only etoricoxib, not celecoxib, is effective for reducing pain intensity at the recovery room up to 8 hours postoperatively.

\section{Conclusions}

Etoricoxib is more effective than celecoxib and placebo for using as preemptive analgesia for acute postoperative pain control in patients underwent arthroscopic anterior cruciate ligament reconstruction.

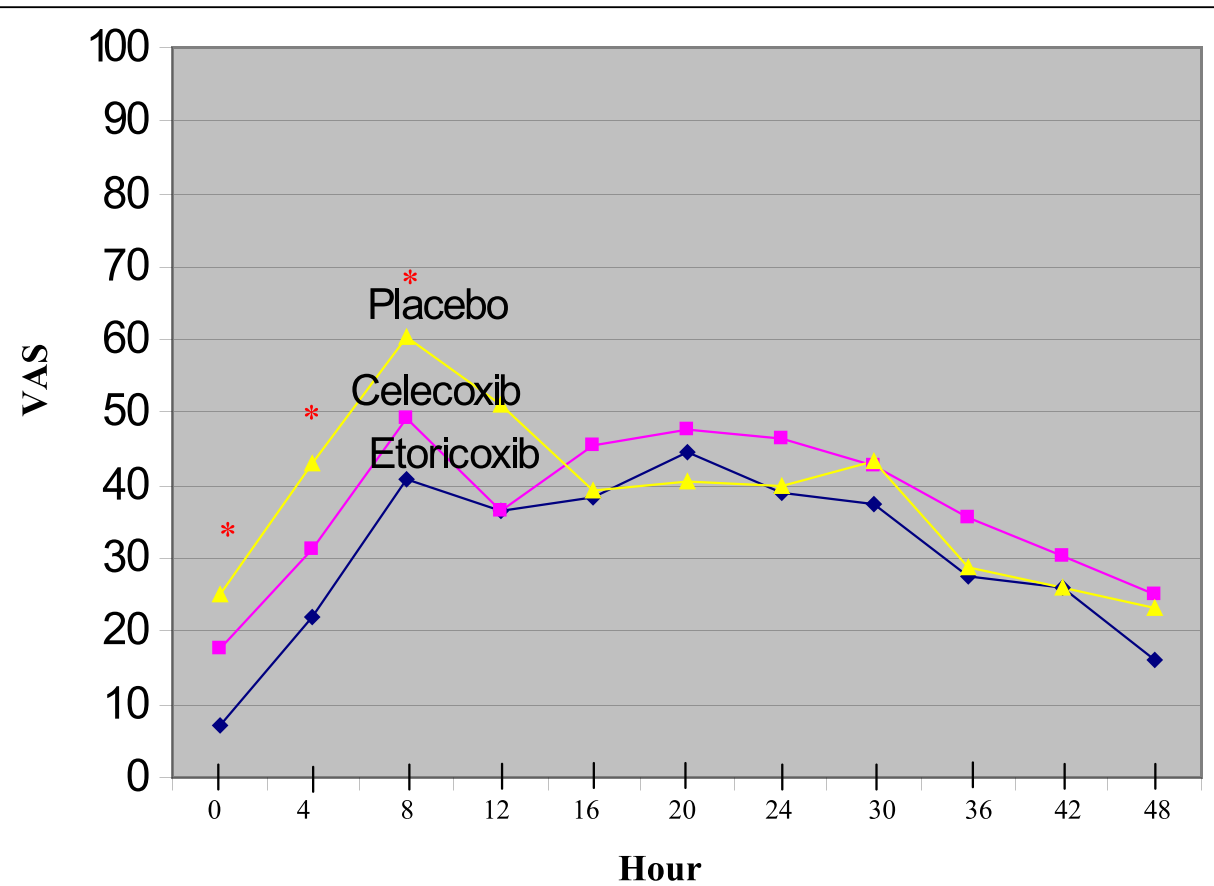

Figure 1 Pain Intensity among each group during 48 hour after surgery. 


\section{Author details}

${ }^{1}$ Department of Orthopaedic Surgery and Physical Medicine, Faculty of Medicine, Prince of Songkla University, Hat Yai, Songkhla, Thailand. ${ }^{2}$ Department of Anesthesiology, Faculty of Medicine, Prince of Songkla University, Hat Yai, Songkhla, Thailand.

Received: 13 October 2009 Accepted: 25 October 2010 Published: 25 October 2010

\section{References}

1. Sinatra R: Role of COX-2 inhibitors in the evolution of acute pain management. J Pain Symptom Manage 2002, 24(1 Suppl):S18-27.

2. White PF: The changing role of non-opioid analgesic techniques in the management of postoperative pain. Anesth Analg 2005, 101:S5-22.

3. Michaloliakou C, Chung F, Sharma S: Preoperative multimodal analgesia facilitates recovery after ambulatory laparoscopic cholecystectomy. Anesth Analg 1996, 82:44-51.

4. Ilan DI, Liporace FA, Rosen J, Cannavo D: Efficy of rofecoxib for pain control after knee arthroscopy: a prospective, randomized, doubleblinded clinical trial. Arthroscopy 2004, 20:813-8.

5. Ekman EF, Wahba M, Ancona F: Analgesic efficacy of perioperative celecoxib in ambulatory arthroscopic knee surgery: a double-blind, placebo control study. Arthroscopy 2006, 22:635-42.

6. White PF: The role of non-opiod analgesic techniques in the management of pain after ambulatory surgery. Anesth Analg 2002, 94:577-85.

7. Puura A, Puolakka P, Rorarius M, Salmelin R, Lindgren L: Etoricoxib premedication for post-operative pain after laparoscopic cholecystectomy. Acta Anaesthesio/ Scand 2006, 50:688-93.

8. Vane JR, Botting RM: New insights into the mode of action of antiinflammatory drugs. Inflamm Res 1995, 44:1-10.

9. Schafer Al: Effects of nonsteriodal anti-inflammatory drugs on platelet function and systematic hemostasis. J Clin Pharmacol 1995, 35:209-19.

10. Stitchtenoth DO, Frolich JC: The second generation of COX-2 inhibitors: what advantages do the newest offer? Drugs 2003, 63:33-45.

11. Chang DJ, Desjardins PJ, King TR, Erb T, Geba GP: The analgesic efficacy of etoricoxib compared with oxycodone/acetaminophen in acute postoperative pain model: a randomized, double blind clinical trial. Anesth Analg 2004, 99:807-15.

12. Kim JT, Sherman O, Cuff G, Leibovits A, Wajda M, Bekker AY: A doubleblind prospective comparison of rofecoxib vs ketorolac in reducing postoperative pain after arthroscopic knee surgery. J Clin Anesth 2005 17:439-43.

13. Desjardins PJ, Grossman EH, Kuss ME, Talwalker S, Dhadda S, Baum D, Hubbard RC: The injectable cyclooxygenase-2-inhibitor parecoxib sodium has analgesic efficacy when administered preoperatively. Anesth Analg 2001, 93:721-7.

14. Tang J, Li S, White PF, Chen X, Wender RH, Quon R, Sloninsky A, et al Effect of parecoxib, a novel intravenous cyclooxygenase type -2 inhibitor, on the postoperative opioid requirement and quality of pain control. Anesthesiology 2002, 96:1305-9.

15. Chan W, Clark AJ, Davis JC, Wolf RS, Kellstein D, Jayawardene S: The postoperative analgesic efficacy and tolerability of lumiracoxib compared with placebo and naproxen after total knee or hip arthroplasty. Acta Anaesthesiol Scand 2005, 49:1491-500.

16. Kellstein D, Ott D, Jayawardene S, Fricke J: Analgesic efficacy of a single dose of lumiracoxib compared with rofecoxib, celecoxib and placebo in the treatment of postoperative dental pain. Int J Clin Pract 2004, 58:244-50.

17. Rassmussen GL, Malmstrom K, Bourne MH, Jove M, Rhondeau SM, Kotey P, et al: Etoricoxib provides analgesic efficacy to patients after knee or hip replacement surgery: a randomized, double-blind, placebo-controlled study. Anesth Analg 2005, 101:1104-11.

18. Buvanendran A, Kroin JS, Tuman KJ, et al: Effects of perioperative administration of a selective cyclooxygenase 2 inhibitor on pain management and recovery of function after knee replacement: a randomized controlled trial. JAMA 2003, 290:2411-8.

19. Clarke R, Derry S, Moore RA, McQuay HJ: Single dose oral etoricoxib for acute postoperative pain in adults. Cochrane Database of Systematic Reviews 2009, 2: CD004309.
20. Derry S, Barden J, McQuay HJ, Moore RA: Single dose oral celecoxib for acute postoperative pain in adults. Cochrane Database of Systematic Reviews 2008, 4: CD004233.

21. Recart A, Issioui T, White PF, Klein K, Watcha MF, Stool L, Shah M: The efficacy of celecoxib premedication on postoperative pain and recovery times after ambulatory surgery: a dose-ranging study. Anesth Analg 2003, 96:1631-5.

22. Issioui T, Klein K, White PF, Watcha MF, Coloma M, Skrivanek G, et al: The efficacy of premedication with celecoxib and acetaminophen in preventing pain after otolaryngologic surgery. Anesth Analg 2002, 94:1188-93.

23. Bingham C III, Sebba A, Rubin B, Ruoff G, Kremer J, Bird S, et al: Efficacy and safety of etoricoxib $30 \mathrm{mg}$ and celecoxib $200 \mathrm{mg}$ in the treatment of osteoarthritis in two identically designed, randomized, placebocontrolled, non-inferiority studies. Rheumatology 2007, 46:496-507.

\section{Pre-publication history}

The pre-publication history for this paper can be accessed here: http://www.biomedcentral.com/1471-2474/11/246/prepub

doi:10.1186/1471-2474-11-246

Cite this article as: Boonriong et al: Comparing etoricoxib and celecoxib for preemptive analgesia for acute postoperative pain in patients undergoing arthroscopic anterior cruciate ligament reconstruction: a randomized controlled trial. BMC Musculoskeletal Disorders 2010 11:246.

\section{Submit your next manuscript to BioMed Central and take full advantage of:}

- Convenient online submission

- Thorough peer review

- No space constraints or color figure charges

- Immediate publication on acceptance

- Inclusion in PubMed, CAS, Scopus and Google Scholar

- Research which is freely available for redistribution

Submit your manuscript at www.biomedcentral.com/submit
C) Biomed Central 